\title{
The relationship between job satisfaction and work performance of sub-district municipality administrators in the eastern region, Thailand
}

\author{
Sakdipath Plikamin ${ }^{1,}$, and Pongsatean Luengalongkot ${ }^{2, *}$ \\ ${ }^{1}$ Candidate in Public Administration at Graduate School of Public Administration, Burapha \\ University, Thailand \\ ${ }^{2}$ Head of Academic Department of Public Administration, Graduate School of Public Administration, \\ Burapha University, Thailand
}

\begin{abstract}
The purpose of this paper is to study the relationship between job satisfaction and work performance of sub- district municipality administrators in the eastern region. The population used in this research is the head and sub-head of sub-district municipality, which have offices in 7 provinces of the eastern region of Thailand, totally 531 people. The sample size consisted of 400 people. Simple random sampling technique was used to collect data. The instruments used for collecting data were questionnaires. In the data analysis, pear son product moment correlation was used to analyse the relationship between job satisfaction and work performance of sub- district municipality administrators in the eastern region by setting statistical significance at the level of 0.01 . The results showed that there is a relationship between job satisfaction and work performance of sub- district municipality administrators in the eastern region.
\end{abstract}

Keywords: work performance, job satisfaction.

\section{Introduction}

As we well know the local administrative organization which is good quality of service bring about the citizen's satisfaction. The competence of organization management or the achievement is the key factors for building confidence and trust in the quality of work to the people who live in each local government. Thus, local administrative organization are try to provide the way for efficient operation even though, a local administrative organization management that there are limitations in many ways underneath successful management which the success factors such as job satisfaction of Sub-district Municipality Executive Officer Operation in the eastern area. The management team of organization that attend the operation, The process of creating engagement with a truly relevant entity is to ensure a common integration in the local area, There is an awakening to make decision to

\footnotetext{
* Corresponding author: pongsate@hotmail.com
} 
perform the good work. The results of the administration of Sub-district municipality are not good enough that impact to service quality cause the people lack their satisfaction and leads to a lack of efficiency in various aspects of management such as infrastructure, economic, natural resources and environment in community. Therefore, the satisfactory administration Sub district Municipality was desirable because lead to the efficiency and effectiveness administration.

The management team of sub- district municipality should know the relationship between job satisfaction and work performance in the eastern region which location of Eastern Economic Corridor (ECC). Job satisfaction refers to the positive feelings that individual value for their welfare that expectation of the person that arose from the comparison with the actions that the person received as required satisfied with the results from the local administration. Katz (2003) [1] stated that job satisfaction related with the work performance which according with Boemer, Eisenbeiss, and Griesser (2007) [2] that study the impact of job satisfaction toward work behavior performance of organization. The results of the research showed that job satisfaction related to work performance of the executor. However, researchers are not confident that job satisfaction related the work performance that context of the municipality in the eastern region. Because of this, management team of local administrative organization are interested in studying the relationship between job satisfaction and work performance of sub- district municipality administrators in the eastern area. The results of the research that help management team of local administrators in municipal level, leading to the guidance of promoting satisfaction and work performance for efficient local management.

\section{Objective}

To study the relationship between job satisfaction and work performance of sub- district municipality administrators in the eastern region.

\section{Hypothesis}

There is relationship between job satisfaction and work performance of sub- district municipality administrators in the eastern region.

\section{Literature review}

To research relationship between job satisfaction and work performance of sub- district municipality administrators in the eastern region. The researches that relate with the work performance as follow.

Concepts of Job Satisfaction related with the work performance. Job Satisfaction related to the work performance, the research as follow Boemer, Eisenbeiss, and Griesser (2007) [2] who study the relation of job satisfaction toward work behavior performance of organization. The research result showed that there are relationship between job satisfaction and work performance.

Research concept work performance as follow Gilmer (1989) [3] The study found that work performance considering the quality of work from the quantity that is finished, and employee behavior from job responsibilities problem solving, and coordination in which the factors affecting are 1) accountability, responsibility refers to a feeling of consciousness in the mind of one's duty and to achieve the best results, including receiving both wrong and wrong results, by performing duties completely, consisting of honesty, operational skills Ability to learn new jobs 2) quality of work It is the amount of work that can be 
completed on time and in accordance with the objectives assembling the quality of work, accuracy, expertise in communication 3) work behavior expressions and actions of employees that directly affect work success also including expression on the environment Relationships with colleagues consist of responsibility, analysis, problem solving. 4) The amount of work is the number of completed works consisting of disclosure and confront. 5) Timely work is the result and amount of work that can be completed on time, consisting of clear goals balance in roles.

Research concept work performance as follow Boemer, Eisenbeiss, and Griesser (2007) [2], Gilmer (1989) [3]

\section{Conceptual framework}

Independent variable Dependent variable

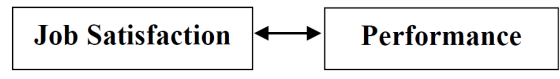

Fig. 1. Conceptual framework.

\section{Method}

The researcher wants to study the relationship between job satisfaction and work performance of sub- district municipality administrators in the eastern region. The researcher uses quantitative research methods from survey research (Questionnaires) in the actual area of the local government organization in the eastern region.

\section{Population}

The population used in this research is the head and sub-head of sub district municipality, which have offices in 7 provinces of the eastern region of Thailand, people as Chantaburi Province, Chachoengsao Province, Chonburi Province, Trat Province, Prachinburi Province, Rayong Province, and Sa Kaeo Province 531 peoples )Department of Provincial Administration, 2018( [4]

\section{Sample and sampling}

The sample for the topic of this research were sub-district municipality executive.The sample size estimation is based on the concept of Sumacher and Lomax (Schumacker, RE and Lomax, RG, 2010, p.49) [5] The sample size is set to 400 people Therefore, the researcher specifies the sample size according to the principle. The sample consisted of 400 people after that, stratified random sampling was conducted in the municipality proportion. (Proportional to Size) after that the simple random sampling technique was used to collect data.

\section{The research instrument}

The questionnaire was used to collect the data. 


\section{The creating and inspecting of the research instrument}

This questionnaire was developed by the professional researcher

1. Find the content validity of the questions according to the questionnaire created by bringing the questionnaire to 5 experts. In order to test and examined for the content validity of the questions according to the set objectives. With improvements as Expert advice

2. Reliability is obtained from a questionnaire that has examined content validity and improved according to expert advice and tried out with a population that is similar to the population but not the population to The purpose of this research was 30 people to find the reliability of the questionnaire from the alpha coefficient formula of Cronbach'sAlpha. The reliability of the questionnaire is 0.8 . It can be considered that this questionnaire is reliable and can be used to collect data.

\section{Results}

The relationship between job satisfaction and work performance was analyzed by pear son product moment correlation and the result as follow:

Table1. The relationship between job satisfaction and work performance.

\begin{tabular}{|c|l|c|}
\hline \multicolumn{2}{|c|}{ Correlation } & \multicolumn{2}{c|}{ Performance. } \\
\hline \multirow{4}{*}{ Job Satisfaction } & $\begin{array}{l}\text { Pearson } \\
\text { Correlation }\end{array}$ & $.615^{* *}$ \\
\cline { 2 - 3 } & Sig. (2-tailed) & .000 \\
\cline { 2 - 3 } & $\mathrm{N}$ & 400 \\
\hline
\end{tabular}

Base on Table 1, Job satisfaction have a high positive relationship on work performance at the statistical significance of 0.01 level. Therefore, the hypothesis is confirmed. There is relationship between job satisfaction and work performance of sub- district municipality administrators in the eastern region.

\section{Conclusion and discussion}

The researcher conclusion and discussion the research results according to the following;

There has a strong positive relationship between job satisfaction and work performance of sub- district municipality administrators in the eastern region. The results revealed that Job satisfaction related on performance. It reflects the current situation that the high level of satisfaction would lead to the high level of work performance of sub- district municipality administrators in the eastern region. It can be implied that if the municipality administrators are highly satisfied with the opportunity for job growth, job security, and job as revealing their individual capabilities, feel trust among the colleagues, their work performance is increased and they are willing to pursue their ability with a strong emotional attached and good results can be given to goal accomplishment and the benefits of the society. This is accordance with Boemer, Eisenbeiss, and Griesser (2007) [2] who study the relation of job satisfaction toward work behavior performance of organization. The research result showed that there are relationship between job satisfaction and work performance. From the meaning of Job satisfaction refers to the positive feelings that individual value for their welfare. As a result of awareness that person assesses the value of the welfare received. We may not notice satisfaction directly, but can be predicted from expression and behavior of personnel in the organization. In addition, satisfaction is also the result. The needs or 
expectations of the person that arose from the comparison with the actions that the person received as required satisfied with the results (Steers, 1991) [6] from the local administration. Municipal level Found that the management has created the acceptance of and encourage people to participate in the operations again, the floor also creates working atmosphere providing employees with a commitment to work, resulting in employees at all levels satisfied with the operation. Resulting in the local performance at the municipal level, the performance level was good. For this reason, satisfaction in work has related on work performance. (Gilmer, 1989) [3]

\section{Recommendation}

From the study to have recommendations follow as

Policy recommendation

The results of this study showed that there has a strong positive relationship between job satisfaction and work performance of sub- district municipality administrators in the eastern region. Therefore, the top executive should have a work plan strategy to improve municipality administrators in each municipality in the eastern region.

Academic recommendations

Participatory action research should be conducted in order to realize the problems of the community development activities of the municipality administrators.

\section{References}

1. Katz, R. A. How job satisfaction and job performance are and are not linked. Job satisfaction. New York: Lexington Books. (2003)

2. Boemer, S. Eisenbeiss, S. A. \& Griesser, D. Follower Behavior and Organizational Performance: The Impact of Transformational Leaders. London, UK: Tavistock Publications. (2007)

3. Gilmer, V. H. Organization : Structure, Processes, Behavior. Dallas, Taxas. Business Publications, Inc. (1989)

4. Department of Provincial Administration). Problem of Performance throughout district Administrative Organization Executive Officials.Bangkok: Prince Damrongrajanubhap Institute of Research and Development and Department of Provincial Administration Ministry of Interior. (2018)

5. Schumacker, R.E. and Lomax, R.G. A Beginner's guide to Structural Equation Modeling. 3rd ed. New York: Lawrence Erlbaum Associate Inc. (2010)

6. Steers, M. R. Introduction to Organization Behavior. New York: Harper Collin Publishers Inc. (1991) 